\title{
CONSIDERAÇÕES ACERCA DO MONISMO DE MÉTODO NA PESQUISA GEOGRÁFICA COM ÊNFASE AMBIENTAL
}

\section{Considerations regarding monistic method in geographical research with environmental emphasis}

\author{
Marco Túlio Mendonça DINIZ1
}

\section{RESUMO}

As questões ambientais se apresentam desde o século passado como os maiores problemas a serem encarados pela humanidade, e em particular, pela ciência. A ciência clássica afirmava ter ela a solução para todas as questões sociais ou naturais do planeta. Na Geografia houve também essa influência do racionalismo que proporcionou, dentro da própria Geografia, uma tentativa de obtenção de métodos que fossem superiores aos outros. A Geografia tem o meio ambiente como objeto de estudo desde a sua fundação, ele esteve um pouco esquecido, mas retorna como questão a ser trabalhada pelos geógrafos no século atual. Discutimos se existe método capaz de esgotar, por si só, as questões de ordem ambiental.

Palavras-chave: Método em Geografia; Meio ambiente; Filosofia da ciência.

\begin{abstract}
Environmental issues exist since last century as the biggest problems to be faced by humankind, and particularly, by science. Classical science was said to have the solution for all natural and social matters in the world. Geography also had the influence of rationalism that led, within itself, to the attempt of obtaining methods that were superior to other ones. Geography has the environment as its study object since its foundation, although the latter has been put aside. However, it returns as an issue to be analyzed by geographers in the current century. We wonder if there is a method able to deal with all issues on environmental order in Geography.
\end{abstract}

Keywords: Geographical methods; Environment; Science philosophy. 
DINIZ, M. T. M. Considerações acerca do monismo de método na pesquisa...

\section{INTRODUÇÃO}

Nas décadas de 1960 e 1970 estava em curso na sociedade mundial uma mudança de mentalidade. Nesta época surgiram por exemplo: os movimentos dos direitos civís, estudantil, feminista, hippie e ambientalista, dentre outros.

Essas alterações se deram também na forma de pensar do meio científico, esse passou a perceber que a compartimentação da ciência em diversas disciplinas sem interconexão dos estudos, como no positivismo clássico, não dava conta dos novos problemas econômicos e (principalmente) ambientais que se apresentaram de uma forma nunca antes experimentada em nível global.

Ficou patente então, para toda a sociedade, a necessidade de uma mudança na filosofia e no modo de vida nos diversos níveis das organizações humanas, para que se pudesse superar a crise já instalada, e para a prevenção de momentos de igual temeridade.

No século XX, após o aparecimento dos estudos da mecânica quântica, cientistas de diversas áreas do conhecimento passaram a compreender que as certezas da ciência moderna poderiam vir a cair por terra. Surge no meio científico a era das incertezas e do indeterminismo, estavam esgotados os métodos de pesquisa científica baseados apenas no modelo newtonianocartesiano, que acreditava que o homem era capaz de explicar tudo o que se passa no mundo, através de uma compartimentação estanque dos estudos científicos.

Em contraponto ao paradigma newtoniano-cartesiano, estudiosos do século passado propuseram outras formas de compreender o mundo através de uma visão do todo. Estas novas formas de entender o mundo surgiram quando da necessidade de explicar os problemas da contemporaneidade ou pós-modernidade, tais como as grandes questões ambientais e principalmente as de caráter social e econômico, jamais experimentadas na história do homem. As novas formas de entender o planeta e os novos métodos de estudo cientifico, estão pautados no diálogo que deve ocorrer entre noções complementares, concorrentes e antagônicas (MORIN, 1998; CAMARGO, 2005).

Nesse contexto a Geografia acabou por participar dessa transformação nas formas de produzir conhecimento, surgindo nessa época a teoria geossistêmica com Bertrand (1972), Sotchava (1977), e a Ecodinâmica de Tricart (1977) como propostas de análise integrada dos sistemas ambientais naturais ${ }^{2}$. Surgiu também a Geografia Crítica ou Radical como proposta para desvendar, quais as reais motivações para a ocorrência de fenômenos de desigualdade social entre os espaços da terra.

A partir de tais considerações é interessante refletir se os atuais problemas que se aprentam à ciência conteporânea podem ser resolvidos por um método único e superior a todos os outros e aplicável a todas as áreas. Mais ainda se considerarmos que os problemas ambientais são os mais procupantes para a atualidade, será que existe uma prosposta única para todas as disciplinas que estudam o meio ambiente, seja ela ligada à ciência clássica ou às surgidas posteriormente?

\section{MEIO AMBIENTE, SUSTENTABILIDADE E RECURSOS AMBIENTAIS}

\section{MEIO AMBIENTE}

Para que se possa iniciar qualquer discussão sobre meio ambiente como objeto de estudo científico é necessário primeiramente recorrer (na filosofia) ao conceito inicial do que seja meio ambiente dessa forma Japiassú e Marcondes (2006, p. 183) afirmam que seja o:

\footnotetext{
Conjunto dos fatores externos (materiais, orgânicos, históricos, culturais ou ideológicos) exercendo uma forte influência nos indivíduos. Em outras palavras, constitui o universo característico de cada espécie, tal como o percebe em seu meio vital e graças ao qual pode agir eficazmente.
}

De tal forma fica evidente que o meio ambiente prescinde da existência do homem, existiu antes e continuará a existir depois da estada humana na Terra. O meio ambiente não é algo exclusivo das sociedades humanas, nem é algo que exclua o homem, entretanto, todo homem obrigatoriamente necessita de um meio ambiente para que possa viver.

2 Todos eles tendo sofrido grande influência da Teoria dos Sistemas Gerais de Bertalanffy (1968). 
DINIZ, M. T. M. Considerações acerca do monismo de método na pesquisa...

Para as sociedades humanas os fatores externos (orgânicos, históricos, climáticos, ideológicos, culturais, de disponibilidade de materiais, etc.) exercem uma forte influência sobre os indivíduos, isso procede desde o início de tais sociedades. Hoje cada vez mais através de suas técnicas os homens passam a moldar muito mais o seu meio ambiente (ou ambiente), esta mudança ocorre de forma a proporcionar um maior conforto para nosso cotidiano. Entretanto o conforto atual pode proporcionar uma situação de desconforto para as gerações futuras, isso acontece quando o homem retira da natureza mais do que ela pode oferecer sem o comprometimento de sua estabilidade. Quando ocorre tal comprometimento temos então uma situação de insustentabilidade.

\section{SUSTENTABILIDADE}

Segundo Afonso (2006, p. 11):

Sustentabilidade implica na manutenção quantitativa e qualitativa do estoque dos recursos ambientais, utilizando tais recursos sem danificar suas fontes ou limitar a capacidade de suprimento futuro, para que tanto as necessidades atuais quanto aquelas do futuro possam ser igualmente satisfeitas.

Etimologicamente a ideia de usar os recursos ambientais, que são finitos para a nossa escala de tempo, sem haver tipo algum de prejuízo é impossível, porém a sustentabilidade ou o desenvolvimento sustentável ${ }^{3}$ enquanto possibilidade de melhor sobrevida para as sociedades humanas deve ser perseguida. É impossível para os homens garantir sua sobrevivência sem usar seu meio ambiente, tal ideia seria a de preservar a todo custo a natureza, o que é impraticável, a alternativa seria então o conservacionismo.

Sobre preservacionismo versus conservacionismo, Afonso (2006, p. 18) comenta "O preservacionismo assumiu a idéia de preservar as áreas virgens de qualquer uso que não fosse recreativo ou educacional. Já o conservacionismo [...] passou a ser o planejamento eficiente e racional dos recursos naturais".

\section{RECURSOS AMBIENTAIS}

A questão ambiental, entretanto, vai além de apenas se utilizar bem dos recursos naturais como fazem empresas que adotam normas de qualidade como o ISO 14001. Encontramos em um manual da norma a seguinte situação que visa atrair outras empresas para a utilização do ISO 14001 como forma de usar de forma racional seus materiais:

\section{P: Que benefícios você obteve?}

R: Nós reduzimos significativamente os gastos de nossa empresa com materiais. Durante este processo, nós também reduzimos nossos custos de descarte de resíduos. Nós conseguimos reciclar energia de calor para reduzir nossas contas de energia. Nós ajustamos os processos de produção e como resultado nos tornamos mais eficientes, e reduzimos o risco de incidentes. Os custos de seguro podem ser reduzidos através da demonstração de uma melhor gestão do risco (BSI, on-line).

Visões como a apontada acima, vieram de propostas aplicadas de estudos das ciências naturais com apoio ao mercado, porém, questões atinentes aos estudos sociais também estão presentes no que diz respeito ao meio ambiente humano, pois há uma distinção entre recurso natural e recurso ambiental, podendo ter o segundo um valor social, difícil de mensurar. Sobre o tema Moraes (2007, p. 17-18, grifos do autor) comenta:

\footnotetext{
Recursos naturais referem-se a produtos, quantidades de materiais depositados na superfície terrestre que se apresentam nos fluxos econômicos como mercadorias, passíveis de terem seus preços aferidos no mercado. Os recursos ambientais referem-se a condições de vida e produção, circunscrevendo fatores de difícil contabilização, como beleza cênica ou originalidade paisagística. O fundamento de tal distinção fica bem evidenciado na diferença entre "terra-capital" (um meio de produção) e a "matéria-terra" (suporte de qualquer atividade produtiva).
} 
DINIZ, M. T. M. Considerações acerca do monismo de método na pesquisa...

Por meio de reflexões como a de Moraes, fica evidente que tratar de meio ambiente no ramo das ciências não é tarefa única de nenhum dos ramos da ciência sendo, portanto, a questão ambiental interdisciplinar e os estudos que tenham como foco o meio ambiente devem ser multidisciplinares.

Moraes afirma que "não seria possível formular uma única proposta de análise da temática ambiental para todas as ciências que estudam a sociedade, pois coexistem nesse conjunto situações diferenciadas" (MORAES, 2005, p. 83).

Pretendemos ir mais além e vamos discutir se há método único para as ciências que estudam a sociedade, ou se há método algum nas ciências como um todo que abarque todas as questões ambientais, pois elas são, obrigatoriamente, de cunho natural e social e como tal ora devem adotar uma, ora outra, alternativa para resolução de distintos problemas em situações também distintas.

\section{CONTRA UM MÉTODO}

Por entendermos que não é novo, nem impossível, nas ciências contemporâneas a ideia de se aplicar mais de um método científico, iremos expor aqui parte do que foi proposto por Paul Feyeraband em seu famoso, controverso e criticado "Contra o método", obra escrita na década de setenta, e considerada a mais importante deste filósofo.

Ao contrário do que possa parecer à primeira vista, Feyerabend e seu anarquismo epistemológico não são contra a ciência ou contra a adoção de métodos na pesquisa científicas, o que Feyeranbend escreveu que seu livro "não é um tratado sistemático; é uma carta a um amigo dirigida às suas idiossincrasias" (FEYERABEND, 2007, p. 7). Tal amigo era Imre Lakatos, que era racionalista e admirador de Popper, posteriormente Lakatos escreveria uma réplica, segundo proposta inicial deste, e as duas cartas seriam publicadas juntas ${ }^{4}$. A parte que cabe a Feyerabend seria uma forte oposição ao "poder" do racionalismo exacerbado e ao neopositivismo popperiano. Por esse motivo Lakatos o chamava de anarquista, obtendo como resposta: "não tive objeções a vestir a capa do anarquista" (FEYERABEND, 2007, p. 8).

Dessa forma a obra de Feyerabend é uma opo- sição à ideia de a ciência ser a única forma de conhecimento válida, opõe-se ainda à ideia de alguns métodos científicos se considerarem as únicas formas de se chegar à verdade. Assim, de forma às vezes demasiado contundente o autor escreve:

\begin{abstract}
Gostaria de defender dois pontos de vista: primeiro, que a ciência pode ficar em pé sobre suas próprias pernas e não precisa de nenhuma ajuda de racionalistas, humanistas seculares, marxistas e movimentos religiosos semelhantes; segundo, que culturas, procedimentos e pressupostos não-científicos também podem ficar em pé sobre suas próprias pernas e deveria ser-lhes permitido fazê-lo, se tal é o desejo de seus representantes. A ciência tem de ser protegida das ideologias, e as sociedades, em especial as democráticas, têm de ser protegidas da ciência. Isso não significa que os cientistas não possam tirar proveito de uma educação filosófica, nem que a humanidade não tirou nem nunca vá tirar proveito das ciências. Contudo, tais benefícios não devem ser impostos; devem ser examinados e livremente aceitos pelos participantes da permuta (FEYERABEND, 2007, p. 8).
\end{abstract}

O autor nos lembra, citando um exemplo, que médicos e sacerdotes tratando com miseráveis de uma cultura completamente desconhecida para os primeiros, perceberam que estes sabem muito mais sobre sua condição do que a crença "na excelência universal da ciência ou da religião organizada" (FEYERABEND, 2007, p. 11). Os estudiosos em questão não se obrigaram a abandonar o conhecimento que trouxeram da universidade e a deixar de pô-los em prática, ao contrário perceberam que poderiam anular problemas materiais e espirituais do inevitável conflito entre culturas, simplesmente unindo seu saber ao saber das pessoas com quem iriam tratar, ou seja, unindo ciência e senso comum para encontrar solução para problemas coletivos.

Na concepção do autor já na década de sessenta "a ciência não era um empreendimento, mas muitos, não podia haver uma política única para dar sustentação a todos eles" (BEN-DAVID 1991, apud FEYERABEND, 2007 , p. 16), em referência ao que mencionamos anteriormente, ou seja, que a partir das décadas de sessenta e setenta a ciência e o mundo como um todo perceberam que a enorme opressão do saber da ciência clássica frente às outras formas de se fazer ciência, e mesmo, frente às outras formas de se perceber o mun-

4 Pena Lakatos ter morrido antes de completarem a obra juntos. 
DINIZ, M. T. M. Considerações acerca do monismo de método na pesquisa...

do, deveria ter um fim, aparecendo essa revolução na ciência junto a outras diversas transformações sociais, como a preocupação com o meio ambiente.

Feyerabend defende que deve haver uma separação entre estado e ciência e que a ciência deveria ser ensinada como uma concepção entre muitas e não como o único caminho para a verdade. A ciência ocidental é hoje suprema às outras formas de conhecimento, não por outro motivo, se não pelo poderio seja militar (a ciência criou os mais bem elaborados instrumentos de extermínio já vistos) e econômico dos países ocidentais.

A ciência é sem dúvida uma das invenções mais maravilhosas da mente humana ${ }^{5}$ porém, esta ciência já praticou, e muito, extermínio de culturas. Deve ser praticada e difundida, porém em comum acordo com os que dela supostamente se beneficiam, pode ser nociva quando trancada, da mesma forma que a ciência aplicada pode ser extremamente benéfica ou maléfica, dependendo aí, de a qual propósito ela serve.

Mill nos explicita a forma com a qual se procede a transição entre as teorias predominantes, como por algum motivo a velha teoria perde espaço e aceitação e uma nova toma seu lugar na sociedade e como ela (a nova teoria) passa a difundir seus braços como próxima opressora frente às outras:

[...] algum corpo particular de doutrina finalmente arregimenta a maioria em torno de si; organiza instituições sociais e modos de ação em conformidade com sigo mesmo; a educação incute esse novo credo à nova geração sem os processos mentais que conduziram a ele; e ele, gradualmente, adquire exatamente o mesmo poder de opressão por longo tempo exercido pelos credos cujo lugar tomou (MILL apud FEYERABEND, 2007 , p. 60 , grifos do autor).

Métodos são como teorias, é fato na história da ciência, que teorias são superadas por outras, assim que uma nova geração a abrace e que estes superem os defensores do status quo, estes por sua vez passam a ter de conhecer a nova teoria, que por sua vez atrai filósofos e cientistas de outras áreas que estão interessados em estar atualizados e na última moda das discussões e do lado "certo" (MILL apud FEYERABEND, 2007 p. 58). Como poderia então um método fixo jamais ser superado, como uma mera proposição poderia dar conta de investigar todas as situações do mundo natural e social? Sendo "realmente racional" homem algum seria capaz de propor tal coisa.

Para Feyerabend "os eventos, os procedimentos e os resultados que constituem as ciências não têm uma estrutura comum; não há elementos que ocorram em toda investigação científica e estejam ausentes em outros lugares" (FEYERABEND, 2007, p. 19, grifo do autor).

A complexidade das relações naturais, e mais ainda, das sociais nos faz interrogações:

\begin{abstract}
Devemos realmente acreditar que as regras ingênuas e simplórias que os metodólogos tomam como guia são capazes de explicar tal "labirinto de interações"? E não está claro que a participação bem-sucedida em um processo dessa espécie só é possível para um oportunista impiedoso que não esteja ligado a nenhuma filosofia específica e adote o procedimento, seja lá qual for, que pareça mais adequado a ocasião? (FEYERABEND, 2007, p. 32, grifo do autor).
\end{abstract}

A reposta parece clara quando afirma que "a pesquisa bem-sucedida não obedece a padrões gerais; depende, em um momento, de certo truque e, em outro, outro" (FEYERABEND, 2007, p. 19) a isso ele denomina oportunismo do pesquisador. - "Nessa pesquisa trabaIhei com esses métodos, categorias e conceitos por serem os por mim considerados os mais adequados aos objetivos e objeto a que me propus estudar", este é um exemplo de uma postura do pesquisador oportunista, estaria ela correta? Ou o correto é seguir um método único para todos os objetos e objetivos de estudo?

$\mathrm{O}$ autor segue com sua tese se apoiando, em nomes como o de Albert Einstein que usa também um termo contundente para classificar o que na sua ótica seria um bom pesquisador:

As condições [...] externas que são colocadas para [0 cientista] pelos fatos da experiência não lhe permitem deixar-se em demasia, na construção de seu mundo conceitual, pelo apego a um sistema epistemológico sistemático como um tipo de oportunista inescrupuloso (FEYERABEND, 2007, p. 19).

5 Necessitamos de um mundo imaginário a fim de descobrir as características do mundo real que pensamos habitar (e o qual, na verdade, talvez seja apenas outro mundo imaginário) (FEYERABEND, 2007, p. 48). Quem tem certeza? 
A ciência somente evoluiu e evolui a partir do momento em que uma tradição é superada por outra, dessa forma os pesquisadores precursores das novas tradições tem de romper com as regras em vigor, seja de propósito ou inadvertidamente. O problema está em proporem novas e a elas se apegarem demasiado e tomarem essas novas regras como nova profissão restrita, tal qual faziam seus predecessores, dessa forma chegarão a novo fim inevitável para suas regras. De tal forma o oportunista (seja o impiedoso de Feyerabend, ou o inescrupuloso de Einstein) tem menor probabilidade de encontrar barreiras intransponíveis em seus empreendimentos.

Segundo Lênin:

Primeiro, que afim de cumprir sua tarefa, a classe revolucionária [isto é, a classe daqueles que desejam mudar quer uma parte da sociedade, como a ciência, quer a sociedade como um todo] tem de ser capaz de dominar, sem exceção, todas as formas ou aspectos da atividade social [tem de ser capaz de entender, e aplicar, não apenas uma metodologia particular, mas qualquer metodologia e qualquer variação dela que se possa imaginar] [...]; segundo, tem de estar preparada para passar de uma à outra da maneira mais rápida e mais inesperada (LÊNIN, apud FEYERABEND, 2007 p. 33, grifos do autor).

Consideramos ser impossível um único método abarcar, ao mesmo tempo, os problemas da natureza e os da sociedade, tal tentativa fatalmente fracassará como a da dialética da natureza de Engels ${ }^{6}$ que tentou aplicar o materialismo histórico-dialético à natureza, o fracasso ocorreu porque o materialismo históricodialético é um método exclusivo das ciências sociais e não universal como pensam os marxistas ortodoxos.

Quanto ao racionalismo (acreditamos que isso serve pra outras correntes), Feyerabend afirma que "até o racionalista mais rigoroso será forçado a deixar de argumentar para recorrer à propaganda e à coerção" (FEYERABEND, 2007, p. 38, grifos do autor), isso é dito no discurso de que a ciência e o racionalismo são opressores por quererem ser absolutos em relação às outras formas de explorar o mundo e assim o fazem para continuar a prevalecer, pois qual a utilidade de um argumento incapaz de influenciar as pessoas?
O racionalista então quando chega a uma situação imprevista se apega ao conhecimento de seu mestre tal qual um dogma, então expressões existentes passam a ser usadas indevidamente, precisam ser distorcidas, mal-empregadas e moldadas em novos padrões para se adequarem e acabam por perder a "razão" em nome de manter sua ideologia e não mais em busca da "verdade". Passa a ficar evidente que essa ideia de superioridade é apenas manobra política. Ou ainda pode ser para "agradar seus baixos instintos, a seu anseio por segurança intelectual na forma de clareza, precisão, 'objetividade' e 'verdade'" (FEYERABEND, 2007, p. 43).

Isso se procede por ser nociva uma postura filosófica dogmática, tal como nos demonstrou Kant (2007, passim) ao afirmar que nem todo conhecimento vem apenas da experiência ou apenas da razão, e sim da relação entre nossa sensibilidade e o conceito que formamos daquilo que sentimos. Antes de Kant os filósofos, teimavam erroneamente, em se agarrar "com unhas e dentes" ou ao racionalismo ou ao empirismo puro, um rechaçando aguçadamente o que o outro propunha.

Feyerabend afirma não avançar no conhecimento e sim dar apoio às pessoas que se aperceberam não ser necessário professar fé a um método único, puro e superior aos outros, e que a ciência não era a única forma de ver a "verdade" no mundo, nem muito menos que o excesso de racionalidade, aliado ao tal método superior serem o único caminho em busca de tal verdade. "todas as metodologias, até mesmo as mais óbvias, têm seus limites" (FEYERABEND, 2007, p. 49).

$\mathrm{O}$ autor diz que nenhuma de suas ideias é inovação e que seriam uma trivialidade para físicos como Mach, Boltzmann, Einstein e Bohr, tendo sido a ideia desses autores "irreconhecivelmente distorcidas pelos roedores neopositivistas e por seus rivais, os roedores pertencentes à igreja do racionalismo 'crítico"'. Tendo Lakatos percebido isso e proposto uma nova teoria da racionalidade e percebendo novos limites para a razão, tal como havia feito Kant para a filosofia.

Feyerabend (2007, p. 42, grifo do autor) afirma:

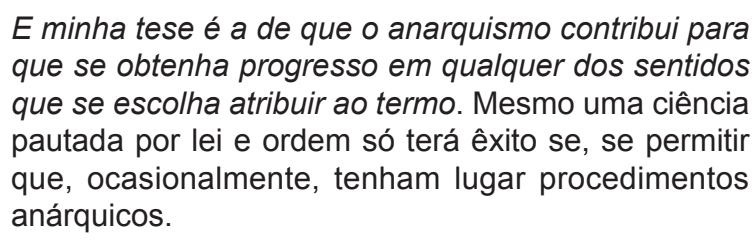

E minha tese é a de que o anarquismo contribui para que se obtenha progresso em qualquer dos sentidos que se escolha atribuir ao termo. Mesmo uma ciência pautada por lei e ordem so terá exito se, se permitir anárquicos.

6 O trabalho de Engels é ótimo no diagnóstico, pois a dinâmica da sociedade, como sabemos hoje, influencia mesmo que de forma pontual, na dinâmica da natureza, porém há questões específicas às geociências como sismicidade e às engenharias como hidráulica, que não cabem métodos das ciências humanas (ENGELS, 1997, passim). 
Para nós é muito pouco provável dominar todos os métodos de nossa ciência. Entretanto os ensinamentos de grandes mestres são válidos na superação de problemas por nós reconhecidos como sendo impossíveis de ser resolvidos através do monísmo metodológico. Problemas tais como o da Geografia realizar pesquisas que almejem obter resultados sintéticos, que transitem entre os ramos das ciências humanas e naturais.

Parece-nos muito caro à Geografia, para nós uma de síntese (ou de elo pelo menos), aderir em algumas de suas pesquisas a essa ideia de Paul Feyerabend,

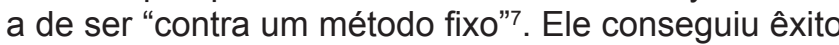
em sua intenção de "ajudar as pessoas", pelo menos a quem sem propõe a trabalhar em pesquisa geográfica com ênfase na análise ambiental como subsídio à gestão territorial.

Depois das reflexões a um nível filosófico mais geral é preciso particularizar o tema no que diz respeito à ciência geográfica, para alcançar tal intento é importante observar se essas ideias são novas na Geografia ou se já algum pesquisador importante tratou da matéria.

\section{GEOGRAFIA COM ÊNFASE AMBIENTAL}

Na Geografia houve também essa influência do racionalismo que proporcionou dentro da própria Geografia uma tentativa de obtenção de métodos que fossem superiores aos outros. Nesse intento houve ascensão e descensão de correntes Geográficas como superiores às outras e foi agravada a dualidade entre Geografias Física e Humana, pois os métodos das duas eram bastante distintos e se apresentavam como os únicos a poder solucionar as questões geográficas, muitas vezes uma Geografia desqualificado a outra como não sendo Geografia.

A geografia tem um papel fundamental no trato com o meio ambiente, pois ela é, talvez, a única ciência que se dedique tanto às questões da natureza, quanto às questões da vida social. Mendonça afirma que "A Geografia [...] desde sua origem tem tratado muito de perto a temática ambiental, elegendo-a, de maneira geral, uma de suas principais preocupações" (MENDONÇA, 2005, p. 8).

Humboldt, que era naturalista, e Ritter, que era historiador, sistematizaram uma ciência que tem como objetivo, dentre outros, estudar as diversas relações entre homem e natureza, exatamente do que tratam os estudos voltados para o planejamento do meio ambiente na concepção atual.

Mendonça argumenta que a maior riqueza do conhecimento geográfico está em sua dualidade, sendo a geografia "um dos últimos lócus do naturalismo nas ciências humanas e também do humanismo nas ciências naturais" (MENDONÇA, 2001, p. 115). Assim, o conhecimento geográfico transcende a dualidade geografia física versus geografia humana, havendo a possibilidade de se chegar pelo menos próximo da integração dessas correntes em nossas pesquisas empíricas.

A ideia de uma Geografia Socioambiental é tratada em um artigo de Francisco Mendonça (MENDONÇA, 2001, passim). Não se trata de um método e sim de uma preocupação metodológica que leva em conta a possibilidade de utilização de vários métodos na pesquisa geográfica.

Nessa concepção o homem deixa de ser um fator e passa a ser um elemento do ambiente (ou meio ambiente), considerando que:
De fato para um geógrafo, a noção de meio ambiente não recobre a natureza, ainda menos a fauna e flora somente. Este termo designa as relações de interdependência que existem entre o homem, as sociedades e os componentes físicos, químicos, bióticos do meio e integra também seus aspectos econômicos, sociais e culturais (VEYRET, 1999 apud MENDONÇA, 2001 p. 117).

Na Geografia socioambiental o termo "sócio" aparece atrelado ao termo "ambiental" para enfatizar a participação da sociedade enquanto parte fundamental nos processos relativos à problemática ambiental na atualidade. Pois os problemas que hoje se descortinam são muito mais complexos do que possam compreender estudos sociais e/ou naturais dissociados uns dos outros.

O tema "meio ambiente" é essencialmente interdisciplinar, Moraes afirma que Interdisplinaridade "não dilui as abordagens específicas e as perspectivas próprias de cada ciência. Ao contrário, o trabalho interdisciplinar toma sentido como a associação de análises peculiares, como uma conjunção que afirma individualidades" (MORAES, 2005, p. 85).

7 Aliás, se fosse esse o nome de sua obra, ela seria vista talvez com menos preconceito, entretanto é provável, também que não tivesse sido tão discutida. 
DINIZ, M. T. M. Considerações acerca do monismo de método na pesquisa...

O cruzamento das individualidades das diversas disciplinas adquire novas qualidades. A interdisciplinaridade não pretende o fim das especificidades e dos objetos particulares de cada ciência e sim a criação de novos objetos que surgem de novas formas de se abordar a realidade.

Vemos em nossa ciência mudanças como a preocupação de geógrafos físicos com questões sociais como Seabra (2007), Mendonça $(2001 ; 2005)$ e Monteiro (1988); e uma preocupação de geógrafos humanos com questões ambientais de ordem natural como Moraes (2005; 2007) e Sposito (2004). Ou seja cada vez mais existem geógrafos preocupados em fazer uma Geografia mais integrada, tomando como base alguns preceitos filosóficos inovadores, contudo, sem que isso os proíba de nortear seus estudos segundo sua especialidade.

Freitas e Cunha afirmam que:

A busca por um pensamento integrador e complexo passa pela utilização do anarquismo metodológico de Feyerabend, como defende Monteiro, onde nenhuma metodologia ou forma de pensamento pode ser desprezada pelo pesquisador, a fim de que o mesmo apreenda o seu objeto de estudo em suas características complexa e holística (FREITAS E CUNHA, 2003, p. 3).

Sposito também se posiciona a favor de Feyerabend e contra as imposições do racionalismo extremo e nos lembra que "as grande inovações teóricas são muito mais fruto do acaso que da ordem" (SPOSITO, 2004, p. 125).

Entretando "A natureza não deve ser mesmo enfocada a partir de métodos específicos aos estudos da sociedade, assim como a sociedade não deve ser a partir de métodos das ciências naturais" (MENDONÇA, 2001, p. 121).

E cabe reafirmar que Geografia Socioambiental não deve prescindir da perspectiva de que há, necessariamente, uma clara distinção entre as leis naturais e os processos sociais.

De tal forma, concordando com Feyerabend, que nem um método é superior ao outro, e sim, que cada um pode ser utilizado oportunamente para resolver determinados problemas; considerando a diferença entre as leis e métodos das ciências naturais e os das ciências sociais, para a perspectiva da Geografia com ênfase ambiental se propõe que sejam utilizados vários métodos para a resolução dos problemas que trans- cendem às questões políticas e da compartimentação da ciência.

Reafirma-se a ideia de que não existe método único na ciência que possa responder sozinho a todas as questões de ordem ambiental que se apresentam na crise em que vivemos. Como Feyerabend e Einstein nos ensinam só um oportunista que se utilize de vários métodos pode se aproximar de uma melhor solução para tais questões, isso se aplica a Geografia, que por natureza, é uma ciência multidisciplinar, ou no mínimo de transição entre as ciências naturais e sociais, e tem se dedicado, desde sua origem aos estudos do meio ambiente.

Para Mendonça:

[...] um estudo elaborado em conformidade com a Geografia Socioambiental deve emanar de problemáticas em que situações conflituosas, decorrentes da interação entre a sociedade e a natureza, explicitem degradação de uma ou de ambas. A diversidade das problemáticas é que vai demandar um enfoque mais centrado na dimensão natural ou mais na dimensão social, atentando sempre para o fato de que a meta principal de tais estudos e ações vai na direção da busca de soluções do problema, e que este deverá ser abordado a partir da interação entre estas duas componentes da realidade (MENDONÇA, 2001, p. 124).

\section{CONCLUSÕES}

Esta posição ousada tem encontrado grande resistência, como de forma prevista, encontrou Feyerabend. Porém, não se trata de irresponsabilidade, pois na perspectiva aqui tratada são importantes o cuidado na escolha dos métodos e técnicas a serem utilizados na pesquisa empírica, além de seriedade, lógica e coerência próprias de um ser pensante que não se detém na limitação de utilizar fórmulas (métodos fixos). A dinâmica e os problemas ambientais não surgem para se adequar a fórmulas, e sim os métodos é que tem de se adequar a eles.

Reiteramos o que Feyerabend disse, o que aqui se apresenta não é novidade, ou seja, não propomos método novo algum só a livre utilização dos métodos já forjados, acrescentamos ainda que não atribuímos mal à especialização da ciência em si, o problema está em não conhecer os resultados da produção de outros especialistas $^{8}$, ou pior, em tentar impor um método único para todas as questões da ciência.

8 Tanto quanto, também, não é bom que um operário desconheça todo o processo de produção em série de uma indústria. 
DINIZ, M. T. M. Considerações acerca do monismo de método na pesquisa...

Quanto à questão do meio ambiente como objeto de estudo da Geografia, em se partindo do princípio que o saber ambiental, além de multidisciplinar, é interdisciplinar e que o profissional que se dedique a tais estudos tem de ter uma visão holística, este é um problema grave para a Geografia que vive pelo menos um grande dualismo: a secular divisão interna Geografia Humana X Geografia Física.

Não seria oportuno discutir este dualismo em esse trabalho, porém considerando que a Geografia tem uma tendência que se aproxima das Ciências Humanas e outra que se aproxima das Geociências, é necessário uma maior integração entre as duas, para tal obra é necessário utilizar e adaptar métodos de pesquisas consagrados nas duas vertentes em nossos estudos empíricos. É salutar ter uma especialidade, porém, sabendo utilizar os outros métodos da ciência conforme o objetivo e objeto do estudo empírico, ou em outras palavras, um "Geógrafo Físico" deve conhecer e utilizar também as técnicas da Geografia Humana e vice-versa.

Desta feita, a Geografia deve contribuir, como mais uma disciplina, na solução de problemas ambientais, sendo ela uma forma de conhecimento que tem estreita relação com a temática ambiental desde a fundação da ciência geográfica. Entretanto, não deve haver de forma interna à Geografia conhecimento ou método que seja inferior ou superior aos outros, mas sim, a possibilidade de serem utilizados conforme o caso para contribuir oportunamente. Pois, nem as abordagens que consideram que as sociedades tenham pouca influencia sobre a dinâmica natural, nem as que consideram a natureza um mero palco para a ação e evolução histórica das sociedades estão, de forma maniqueísta, corretas ou erradas, ou ainda, são superiores ou inferiores umas as outras, ao contrário, são todas limitadas e parciais. Sendo o saber usar estas peculiaridades o grande trunfo do Geógrafo que estuda as questões ambientais.

\section{REFERÊNCIAS}

AFONSO, C. M. Sustentabilidade: Caminho ou utopia? São Paulo: AnnaBlume, 2006.

BERTALANFFY, Ludwig von. Teoria Geral dos Sistemas. Petrópolis: Vozes, 1968.

BERTRAND, Georges. Paisagem e Geografia Física global: esboço metodológico. Tradução de Olga Cruz. Cadernos de Ciências da Terra, São Paulo: USP-IGEOG, n. 43, 1972.

BSI. O que é ISO 14001? Disponível em: <www.bsibrasil.com. br>. Acesso em: 14/2/2008.

CAMARGO, Luis. H. R. de. A ruptura do meio ambiente: Conhecendo as mudanças ambientais do planeta através de uma nova percepção da ciência: A Geografia da complexidade. Rio de Janeiro: Bertrand Brasil, 2005.

ENGELS, Friedrich. Dialética da natureza. Rio de Janeiro: Paz e Terra, 1997.

FEYERABEND, P. K. Contra o método. Tradução de: Cezar Augusto Mortari. São Paulo: Editora da UNESO, 2007.

FREITAS, M. W. D.; CUNHA, S. B. Fisiologia da Paisagem e Geossistemas: Contribuições Metodológicas Integradoras do Pensamento Geográfico. In: SIMPÓSIO BRASILEIRO DE GEOGRAFIA FÍSICA APLICADA, 10., 2003, Rio de Janeiro. Anais... Rio de Janeiro: UERJ, 2003. Disponível em : <http:// geografia.igeo.uerj.br/xsbgfa/cdrom/eixo3/3.2/ 269/269.htm>. Acesso em: 25/04/2007.

JAPIASSÚ, H.; MARCONDES, D. Dicionário Básico de Filosofia. 4. ed. Rio de Janeiro: Jorge Zahar, 2006.
KANT, I. Crítica da Razão Pura. Col. Fundamentos do Direito. São Paulo: Ícone Editora, 2007.

MENDONÇA, Francisco. Geografia sócio-ambiental. Terra Livre, São Paulo: AGB, n. 16, p. 139-158, $1^{\circ}$ semestre/2001.

Geografia e Meio Ambiente. 8. ed. São Paulo: Contexto, 2005. (Caminhos da Geografia).

MONTEIRO, C. A. F. Travessia da crise (tendências atuais na geografia). Revista Brasileira de Geografia, Rio de Janeiro, ano 50, n. especial, t. 2, p. 19-28, 1988.

MORAES, A. C. R. Meio Ambiente e Ciências Humanas. 4. ed. São Paulo: Annablume, 2005.

Contribuições para a gestão da zona costeira do Brasil: Elementos para uma Geografia do Litoral Brasileiro. 2 ed. São Paulo: Anna Blume, 2007.

MORIN, Edgard. Ciência com consciência. Rio de Janeiro: Bertrand Brasil, 1998.

SEABRA, G. Geografia: fundamentos e perspectivas. 4. ed. João Pessoa: Editora Universitária/UFPB, 2007.

SOTCHAVA, V. B. O estudo dos geossistemas. Métodos em Questão, n. 16, São Paulo: IGEOG-USP, 1977.

SPOSITO, E. S. Geografia e Filosofia: contribuição para o ensino do pensamento geográfico. São Paulo: Editora da UNESP, 2004.

TRICART, J. Ecodinâmica, Rio de Janeiro: FIBGE-SUPREN, 1977. 
